\title{
Conexões
}

\section{A Praxiologia Motriz e suas contribuições ao debate científico da Educação Física}

\author{
Marco Antonio Coelho Bortoleto ${ }^{1}$ \\ João Francisco Magno Ribas ${ }^{2}$ \\ Jorge Ricardo Saraví ${ }^{3}$
}

Dedicamos este Dossiê à memória do Prof. Dr. Ademir de Marco (1954-2020) corresponsável por abrir as portas para o debate da Praxiologia Motriz no contexto brasileiro.

Para nós é uma imensa alegria compartilhar com todos os leitores e leitoras um novo número da revista Conexões: Educação Física, Esporte e Saúde, neste caso, dedicado a Praxiologia Motriz e suas contribuições à Educação Física. Desde a publicação dos textos pioneiros de Pierre Parlebas dos anos cinquenta e sessenta do século XX, muito tempo já passou (PARLEBAS, 2017). Esse percurso tem refletido em inúmeras publicações e investigações (livros, teses de doutorado e de mestrado, artigos etc.), assim como, em eventos científicos (Congressos, seminários e cursos de pós-graduação), que marcaram o longo caminho que conduziu até esta publicação que estamos apresentando.

Por sua vez, essa produção coletiva também surge após muitos anos de intercâmbios entre investigadores e instituições de diferentes países, no seio de uma comunidade acadêmica que vem crescendo e expandindo suas colaborações. Nesse sentido, há aproximadamente uma década, foi possível constituir uma sociedade científica, a Associação Internacional de Praxiologia Motriz (AIPRAM) ${ }^{4}$, que tem trazido contribuições extremamente importantes para a área. Também entendemos que este dossiê ganhou importância singular nos atuais contextos de isolamento que vive a grande maioria dos países do mundo

\footnotetext{
1 Universidade Estadual de Campinas.

2 Universidade Federal de Santa Maria.

3 Universidad Nacional de La Plata.
}

Contato: bortoleto@fef.unicamp.br

\footnotetext{
${ }^{4}$ A criação da AIPRAM aconteceu no dia 12 de maio de 2010 na cidade de Caen (França) durante o XIII Colóquio Internacional de Praxiologia Motriz. Na ocasião, o Estatuto da Fundação foi assinado e um Conselho Diretivo provisório nomeado. Mais informações em: https://www.univchlef.dz/aipram/index.php/histoire-aipram/
} 
por conta da pandemia de Covid-19, visto que se tornou uma excelente oportunidade para fortalecer e aprofundar laços acadêmicos da comunidade internacional.

Com isso, ter um dossiê completo dedicado às pesquisas e reflexões com base na Praxiologia Motriz e que seja publicado na América Latina, não é fruto do acaso ou sorte. Há mais de dez anos, a região lidera ações relacionadas, tanto à produção acadêmica de teses e investigações, quanto à organização de eventos acadêmico-científicos sobre o tema. A primeira iniciativa regional foi o "I Seminário Brasileiro de Praxiologia Motriz", realizado em 2008 na Universidade Federal de Santa Maria (UFSM). No ano seguinte, foram realizados o "II Seminário Nacional Brasileiro de Praxiologia Motriz" e o "I Seminário LatinoAmericano de Praxiologia Motriz"5 na Universidade Estadual de Campinas. Anteriormente, os primeiros eventos específicos de Praxiologia Motriz ocorreram a partir de 1995 na Europa e eram denominados "Seminário Internacional" por envolver principalmente investigadores franceses, espanhóis e portugueses, naquela ocasião. A primeira edição foi realizada no Instituto Nacional de Educação Física da Catalunha (INEFC, Centro de Lleida) na Espanha. Depois que as edições seguintes do seminário internacional foram realizadas em cidades da Espanha e da França, a XIV edição aconteceu pela primeira vez na América Latina na cidade de La Plata, Argentina, e também foi chamada de II Seminário Latino Americana em função da numerosa participação de países latinoamericanos $^{6}$. Em 2014 foi realizada a primeira edição do Congresso Internacional de Praxiologia Motriz na cidade de Manaus (UFAM, Brasil) ${ }^{7}$, indicando que os estudos praxiológicos ganharam repercussão e raízes na América Latina. Por fim, parece-nos relevante destacar a realização em 2015 do III Seminário LatinoAmericano Internacional de Praxiologia Motriz e do III Seminário Brasileiro de Praxiologia Motriz, organizado novamente na UFSM (Santa Maria-RS, Brasil) ${ }^{8}$, reunindo um grupo cada vez maior de pesquisadores.

Por outra parte, as publicações científicas fundamentadas em/na Praxiologia Motriz têm aumentando na América Latina, como vemos, por exemplo, nos inúmeros livros publicados ${ }^{9}$. De forma mais específica, foram

\footnotetext{
${ }^{5}$ Ambos eventos se realizaram sob a organização e gestão de Marco Antonio Coelho Bortoleto (UNICAMP) e João Francisco Magno Ribas (UFSM).

${ }^{6}$ O XIV Seminário Internacional e II Latinoamericano de Praxiologia Motriz: Educação Física e contextos críticos teve como presidente do comitê organizador Raúl Gómez (UNLP) e como vice presidente Jorge Saraví (UNLP). Mais informação em: http://seminprax.fahce.unlp.edu.ar/programa

7 Sob coordenação de Artemis de Araújo Soares (UFAM).

8 Realizado sob a liderança de João Francisco Magno Ribas (UFSM). Mais informações sobre o evento disponível em: https://www.ufsm.br/cursos/pos-graduacao/santa-maria/ppgef/eventos/iiiseminario-latino-americano/

${ }^{9}$ Dentre estes livros podemos mencionar Jogos e Esportes: fundamentos e reflexões da Praxiologia Motriz organizado por Ribas (2008) e Análise Praxiológica do Rugby. Estudo do núcleo tático (RUFFINO, 2007). Mais recentemente, destacam-se as obras coletivas Educação Física Escolar e Praxiologia Motriz: entendendo como práticas corporais organizada por Ferreira e Ramos (2017) e Praxiologia Motriz na América Latina. Contribuições para a didática na Educação Física coordenado por Ribas (2017).
} 
várias as publicações periódicas de diferentes países que precederam este Dossiê e que dedicaram suas páginas a temas relacionados com a Praxiologia Motriz. De forma pioneira, a Revue EPS, que, a partir de 1967 e por mais de uma década, publicou os primeiros artigos de Pierre Parlebas ${ }^{10}$. Na Espanha, a revista Apunts publicou diversos artigos sobre praxiologia no Número 16-17 (1989), no Dossiê intitulado "Educação Física, pedagogia renovadora". Alguns anos depois, no número 32 da mesma revista (1993), surge o Dossiê "Praxiologia: o estudo das práticas expressivas, esportivas e lúdicas", coordenado por Francisco Lagardera. Na Argentina, a revista Lecturas: Educación Física y Deportes, começou com a publicação de um texto de Pierre Parlebas no número 7 - Ano 2 (1997) ${ }^{11}$, em uma seção dedicada a artigos sobre Praxiologia Motriz, em particular vários deles de autoria de José Hernández Moreno. A revista Ethologie, criada em 1982, passou a receber artigos escritos por praxiólogos até que em 2009 passou a se chamar Ethologie et praxeologie.

Posteriormente, começaram a surgir publicações que buscavam refletir a especificidade da Ciência da Ação Motriz. Uma das primeiras é a Praxiologia Motriz, revista científica de las actividades físicas, los juegos y los deportes. Seu primeiro e único número foi lançado em 1996, sob a direção de Fernando Amador Ramírez e foi editado pela Universidade de Las Palmas de Gran Canaria. Em 2004 foi publicada a obra Praxiologia Motriz no Brasil, apresentada pelo organizador José Ricardo da Silva Ramos como uma revista que não teve continuidade. Mais recentemente, a partir de 2008, a revista Acción Motriz editada por iniciativa de José Hernández Moreno e Juan Pedro Rodríguez Ribas, e publicada na Espanha pela ACCAFIDE (Associação Científico-Cultural em Educação Física e Esportes), conseguiu manter a periodicidade até os dias atuais. Esta última revista que é de acesso livre ${ }^{12}$, vem crescendo com muita força, tornando-se um espaço onde publicam os especialistas em Praxiologia Motriz. Por sua vez, e principalmente na última década, houve um aumento significativo no número de publicações de artigos científicos que dialogam com a Praxiologia Motriz, muitos deles em periódicos latino-americanos, evidenciando 0 crescimento de estudos praxiológicos na literatura especializada nesta região ${ }^{13}$.

Esta breve síntese mostra o crescimento científico da Praxiologia Motriz e sua maior presença na comunidade acadêmica internacional, uma organização mais sistemática de seus pesquisadores e a consolidação de eventos internacionais temáticos. Neste sentido, entendemos que o presente dossiê se

\footnotetext{
10 A maior parte desses artigos foi posteriormente publicada em formato de livro pela própria revista EPS, em um Dossiê especial que foi reeditado em diversas ocasiões (PARLEBAS, 1990). Vários desses textos foram publicados recentemente com a edição e tradução de Raúl Martínez de Santos (PARLEBAS, 2017).

${ }^{11}$ A lista completa de artigos que os editores colocam na temática da "praxiologia" está disponível em: https://www.efdeportes.com/efdo/b-prax.htm

12 Ver o site da revista Acción Motriz, disponível em: www.accionmotriz.com/

13 Entre outras, podemos mencionar a revista Movimento, do Brasil (disponível em https://seer.ufrgs.br/Movimento) ou a revista Impetus, da Colombia (disponível em http://revistaimpetus.unillanos.edu.co/impetus/index.php/Imp1).
} 
une ao referido movimento dando continuidade ao debate praxiológico. Parecenos, ademais, que a Educação Física deve manter-se permeável à distintas perspectivas teóricas, dialogando com as mudanças e avanços que vêm acontecendo no âmbito da Praxiologia Motriz na América Latina e em outras regiões. Essa edição temática é a expressão de diferentes olhares e contribuições ao debate científico da Educação Física.

Há aproximadamente três anos começamos a desenvolver o projeto apresentado nessa oportunidade, concretizado sob o formato deste dossiê. Com ele desejávamos criar um espaço que respondesse à crescente demanda da comunidade acadêmica e ao interesse dos estudiosos de múltiplos países. A resposta a convocatória da Revista Conexões foi significativa tanto na quantidade como na qualidade dos artigos, como veremos mais adiante. Ao longo de muitos meses recebemos diferentes textos, os quais foram avaliados pelo sistema duplo-cego, por um conjunto de especialistas internacionais. É importante mencionar que este dossiê não contou somente com a colaboração de investigadores/as do campo da Praxiologia Motriz, mas também de outros/as acadêmicos/as que, com distintas especialidades ou marcos teóricos, participaram na condição de avaliadores/as. Essa decisão nos parece que ajuda a outorgar maior solidez científica ao dossiê, validando os trabalhos publicados e consolidando o já anunciado crescimento da área.

Participaram com o envio de diferentes contribuições um total de 43 autores/as e coautores/as. Contamos ainda com a colaboração de 45 revisores/as. Em outras palavras, para o desenvolvimento deste dossiê (sem contabilizar editores/as e colaboradores/as da própria revista) coautuaram um grupo de 60 acadêmicos/as. A todos/as, nosso mais sincero agradecimento pelo empenho dedicado a este árduo trabalho. Esses especialistas pertencem a mais de 30 instituições de sete países diferentes. Devemos um especial agradecimento, à equipe editorial da Revista Conexões, particularmente à Andréia Manzato Moralez (Editora técnica) e ao Prof. Dr. Edivaldo Góis Junior, Editor chefe.

Cabe indicar que além do processo habitual de revisões, correções e edição, este dossiê se torna público num contexto muito particular: a maioria dos docentes-investigadores e profissionais da Educação Física, Recreação e Esporte se encontra trabalhando em suas casas por razão da Pandemia COVID-19. Nessas condições, entendemos que as revistas científicas e editoras que publicam seus materiais no formato Open Access assumem uma importância capital, ao permitir/facilitar o acesso livre e gratuito à valiosos textos para a investigação, atualização e a capacitação dos/as especialistas interessados/as.

De modo geral, apresentamos um compêndio de artigos que engloba diferentes perspectivas metodológicas, análises de distintos esportes e outras práticas corporais, debates relevantes sobre aspectos conceituais e específicos sobre a lógica interna de diferentes situações motrizes. O dossiê está composto 
por 23 textos, dos quais, dezenove são artigos, duas entrevistas e duas resenhas de livro. No que tange aos artigos, agrupamos em três grandes eixos. O primeiro trata de aspectos conceituais que articulam com o campo da Educação Física. Outros manuscritos apresentam como foco o debate e sistematização do trabalho pedagógico e da didática. O último grupo de os textos que abordam estudos de lógica interna de distintas manifestações corporais.

Cabe destacar que para esta ocasião tão particular contamos com um artigo do fundador desta perspectiva científica, o Doutor Pierre Parlebas, Professor Emérito da Universidade de Paris V, França. Se trata de um texto escrito há alguns anos e que havia permanecido inédito, intitulado "Educación Física y praxiología motriz" (Educação Física e Praxiologia Motriz) e que foi revisado e atualizado para ser incluído neste dossiê. No referido artigo, Parlebas retoma o debate da falta de um objeto específico da Educação Física, indicando a teoria da ação motriz como alternativa para a área. Nessa mesma linha de mostrar a articulação da Praxiologia Motriz com a Educação Física, Pablo Aires Araújo, Silvester Franchi e Pere Lavega apresentam os principais conceitos da Praxiologia Motriz em especial, no contexto escolar no artigo "Praxiologia motriz - Educação física como educação das condutas motrizes". Os autores Aaron RilloAlbert, Cristòfol Salas-Santandreu e Enirc Ormo-Ribes, na "Entrevista a Pere Lavega, heredero de la excelencia intelectual de Pierre Parlebas" (Entrevista com Pere Lavega, herdeiro da excelência intelectual de Pierre Parlebas) conseguem mostrar a grande influência e importância deste pesquisador no processo de articular o debate com o campo da Educação Física por conta de seus estudos teóricos e de investigações aplicadas. Nessa mesma linha, os autores Unai Saez de Ocariz Granja e Pere Lavega entrevistam a outro importante pesquisador da Praxiologia Motriz, no texto "Entrevista a Francisco Lagardera, referente intelectual de la educación física y de la ciencia de la acción motriz" (Entrevista com Francisco Lagardera, referente intelectual da Educação Física e da Ciência da Ação motriz). A perspectiva dos protagonistas que buscam situar a teoria da ação motriz em relação ao campo da Educação Física se completa com a resenha "Introducción a la praxiología motriz: Reseña del libro" (Introdução à Praxiologia Motriz: resenha do livro)" realizada por Rafael Luchoro-Parrilla, Cristófol SalasSantandreu e Verónica Muñoz-Arroyave, relevante referência para divulgação em língua espanhola do conhecimento praxiológico, que teve como destaque a revisão de conceitos básicos da teoria e apresentam exemplos de aplicação. Por fim, Raúl Martínez-Santos no artigo "Signos, metáforas y educación física: conectando Peirce y Parlebas mediante la acción motriz" (Signos, metáforas e educação física: conectando Peirce e Parlebas através da ação motriz) realiza a articulação da Praxiologia Motriz com a Educação Física mediante a lógica triádica de Peirce considerando os três símbolos: Educação Física, ação motriz e Praxiologia Motriz.

O segundo grupo de artigos, estabelece a relação do conhecimento praxiológico com distintos temas atinentes à organização do trabalho pedagógico 
e da didática. Observa-se nestes estudos a teoria da ação motriz em movimento, analisados em contextos e situações pedagógicas concretas. Uma parte desses estudos mostra a relevância da Praxiologia Motriz em documentos oficiais do campo da Educação Física. O artigo de Roberto Stahringer, "La problemática de la especificidad - exclusividad disciplinar en la educación física: aportes de la praxiología motriz y presentación de un caso explicativo" ( $O$ problema da especificidade - exclusividade disciplinar na educação física: contribuições da praxiologia motriz e apresentação de um caso explicativo", destaca as contribuições da praxiologia motriz em Currículos Institucionais de Formação de docentes em Educação Física na Argentina. Em "Principios y subprincipios para un currículo praxiológico de educación física' (Princípios e subprincípios para um currículo praxiológico de educação física) de Raúl Martínez-Santos, Astrid Aracama, María P. Founaud e Asier Oiarbide, analisam princípios e subprincípios em um currículo que norteie a reflexão pedagógica, a organização didática e a intervenção. Por fim, no contexto brasileiro, os autores Lidiane Soares Bordinhão, Bruno Minuzzi Lanes, Silvester Franchi, William Daniel Bitencourt analisam o recente documento norteador da educação brasileira, Base Nacional Comum Curricular (BNCC), no texto "Praxiologia Motriz e as dimensões de conhecimento da BNCC: primeiras aproximações", um tema ainda em pleno debate.

Ainda relacionado com aspectos pedagógicos, outro grupo de artigos trata de estabelecer uma relação direta com práticas corporais como voleibol, ginástica para todos, iniciação esportiva e equoterapia. A análise praxiológica do voleibol aparece em dois artigos. Por um lado, na "Resenha crítica da obra Praxiologia Motriz e Voleibol: elementos para o trabalho pedagógico" foi resenhado por Felipe Menezes Fagundes na qual destaca aspectos centrais da obra e suas implicações para o trabalho pedagógico. Por outro lado, Raquel Valente de Oliveira, Bruno Minuzzi Lanes e João Francisco Magno Ribas analisam a ação do levantador a luz da teoria praxiológica em "Organizando as ações ofensivas: informações provenientes do levantador que orientam a atuação de companheiros e adversários no voleibol". A prática pedagógica da ginástica na sua forma não-competitiva e sociomotriz, consiste em outra manifestação corporal analisada por Marco Antonio Coelho Bortoleto e Fernanda Raffi Menegaldo no artigo "Ginástica para Todos: o que a Praxiologia Motriz diz sobre isso?". Os autores Deyvid Tenner de Souza Rizzo, Rogerio Zaim-de-Melo e Marcelo José Taques realizam outra importante sistematização teórica no texto "Jogos e/na iniciação esportiva: princípios e reflexões na ótica da praxiologia motriz" estabelecendo aproximações entre a Praxiologia Motriz, o jogo e a iniciação esportiva. Para finalizar os estudos que tratam dos aspectos didáticos e pedagógicos das práticas corporais, José Ricardo da Silva Ramos, autor do artigo "Reflexões sobre a prática interativa na Equoterapia à luz da Praxiologia Motriz", apresenta uma proposta de uma práxis terapêutica com uso de cavalos tendo como base conceitos da Praxiologia Motriz. 
As relações da Praxiologia Motriz com a organização do trabalho pedagógico e da didática também tiveram como ênfase os temas atinentes aos conflitos, a criatividade e ao uso dos espaços escolares. Rodrigo Gonçalves Vieira Marques, Glauco Nunes Souto Ramos e Lilian Aparecida Ferreira, no artigo "Conflitos em jogos de futsal e de handebol: reflexões praxiológicas" identificaram e analisaram a conflitividade gerada entre estudantes na prática de futsal e handebol. Ainda tendo como cenário o contexto escolar, Flávia Carneiro Franco com o artigo "Discurso y praxis en educación física escolar: (des)conocimiento del entorno natural" (Discurso e práxis na educação física escolar: (des)conhecimento do entorno natural) apresenta uma pesquisa com a qual estabeleceu a relação entre o projeto educativo e o uso do espaço nas situações motrizes realizadas na Educação Física em escolas públicas e privadas. Por fim, o tema da criatividade é analisado no artigo "Opciones de creatividad durante la práctica de actividades físicas de expresión y deportes artísticos desde la Spórtica" (Opções de criatividade durante a prática de atividades físicas de expressão e esportes artísticos a partir da Spórtica) de autoria de Juan Pedro Ribas e Mercè Mateu-Serra, indicando possibilidades concretas para todos que atuam no campo da expressão corporal e/ou nos esportes que incluem elementos artístico-expressivos.

O estudo da lógica interna de manifestações corporais consiste em uma das grandes contribuições do conhecimento praxiológico para o campo da Educação Física. No seguinte grupo de artigos, relacionamos seis manuscritos que analisam a dinâmica de funcionamento de distintas práticas corporais. A relação da lógica interna com o aspecto cultural do jogo tradicional presente num clássico da literatura mundial foi tratada por José Hernández Moreno, Ulises Castro Núñez e Rómulo Díaz Díaz no artigo "El juego en cien años de soledad: análisis etnomotor" (O jogo na obra cem anos de solidão: Análise etnomotriz). Dihuen Cibeyra e Jorge Ricardo Saraví apresentam os resultados de uma investigação qualitativa no texto "Lógica interna del surf" (Lógica interna do surf) analisando a maneira com que os praticantes do surf não competitivo se relacionam com o meio, com os outros, com o material e com o tempo. Em "Lógica interna de los "crescendos" en los números de los espectáculos de Cirque du Soleil (19862005)" (Lógica interna dos "crescendos" nos números dos espetáculos do Cirque du Soleil - 1986-2005)", a investigadora Mercè Mateu Serra analisa e discute como a evolução da intensidade dramática das cenas e suas criações modula a lógica interna dos espetáculos circenses. Por outro lado, Erick Lisboa de Mesquita, Rodrigo Wanderley de Sousa-Cruz, Silvester Franchi e Leys Eduardo dos Santos Soares analisaram as aprendizagens geradas a partir do entendimento da dinâmica do jogo do squash, considerando as interações entre jogadores, espaços e implementos no artigo intitulado "A Lógica Interna do Squash e as Aprendizagens do Jogo". Nessa mesma linha de orientar o processo de ensino-aprendizagem a partir da lógica interna, o artigo "Aproximações entre o Handebol e a Praxiologia Motriz: proposta de ensino-aprendizagem com base nas problemáticas emergentes da Lógica Interna do jogo" de autoria de Eduardo 
Ivan Friedrich e Felipe Menezes Fagundes realiza um estudo do handebol. Por fim, Vagner Augusto de Oliveira Schmidt e Raquel Valente de Oliveira apresentam e analisam "A lógica interna das lutas corporais e suas implicações no processo de ensino-aprendizagem nas aulas de Educação Física escolar".

Conforme indicado nos parágrafos anteriores, a Praxiología Motriz tem mostrado uma presença significativa nos debates da Educação Física, principalmente na Europa, e, também, com cada vez mais força na América Latina. Diferentes documentos oficiais publicados recentemente em vários países da América Latina, particularmente sobre propostas curriculares, reforçam a vigência desta teoria e a sua relevância para a Educação Física do século $X X I^{14}$. Neste sentido, o dossiê que apresentamos possui grande atualidade, além de efetuar valiosas contribuições ao campo das ciências socioculturais dos jogos, dos esportes e de outras práticas corporais.

Esta produção que hoje se torna pública aos leitores e leitoras foi engendrada em circunstâncias de crise para a humanidade, num momento de ameaças crescentes para as universidades em particular e para a ciência em geral. Entendemos que neste contexto, o presente dossiê representa uma mostra de esperança da força do trabalho coletivo a favor da educação e do conhecimento científico.

Desejamos a todos e todas, uma excelente leitura!

\section{REFERENCIAS}

FERREIRA, Lilian Aparecida; RAMOS, Glauco Nunes Souto. (Org). Educação Física escolar e Praxiologia Motriz: compreendendo as práticas corporais. Curitiba: Editora CRV, 2017. Coleção Educação Física: formação para o cotidiano escolar, v. 22.

PARLEBAS, Pierre. Problemas teóricos y crisis actual en la Educación Física. Lecturas: Educación Física y Deportes, Buenos Aires, v. 2, n. 7, Octubre, 1997.

https://www.efdeportes.com/efd7/pparl7.htm

PARLEBAS, Pierre. Activités physiques et éducation motrice. Dossier EPS 4, v. 27, p. 6075. Paris, Éditions Revue Éducation Physique et Sport, 1990.

PARLEBAS, Pierre. La aventura praxiológica: ciencia, acción y educación física. Traductor y editor Raul Martinez de Santos. Junta de Andalucía, Consejería de Turismo y Deporte, 2017.

RIBAS, João Francisco Magno (Org.). Praxiologia Motriz na América Latina. Aportes para a didática na Educação Física. Ijuí: Editorial Unijuí, 2017. Coleção Educação Física.

14 A modo de ejemplo podríamos mencionar no Brasil, las propuestas gubernamentales desarrolladas y presentadas por el gobierno del Rio Grande do Sur (2018) y la reciente BNCC (2017). 
RIBAS, João Francisco Magno; FRANCO, Flávia. Praxiologia Motriz e a organização do trabalho pedagógico e da didática na Educação Física: Entrevista com Pierre Parlebas, professor da Universidade Paris Descartes (Paris V - Sorbonne Cité). Movimento (ESEFID/UFRGS), Porto Alegre, v. 26, p. e26008, 2020. Disponível em:

https://seer.ufrgs.br/Movimento/article/view/94580. Acesso em: 28 ago. 2020.

RUFFINO, J. D. Análisis Praxiologico del Rugby. Estudio del núcleo táctico. Tucumán: Edición de la Facultad de Educación Física, Universidad Nacional de Tucumán, 2007.

SARAVÍ, Jorge Ricardo. A praxiologia motriz: presente, passado e futuro. Entrevista com Pierre Parlebas. Movimento (ESEFID/UFRGS), Porto Alegre, v. 18, n. 1, p. 11-35, jan./mar., 2012. Disponível em: https://seer.ufrgs.br/Movimento/article/view/27065. Acesso em: 28 ago. 2020. 